\section{The killing fields}

\author{
Plan to cull badgers in England shows the new \\ government does not respect scientific advice.
}

$\mathrm{W}$

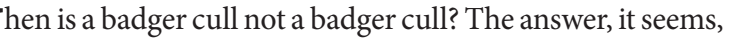
is when it is one arranged by the new UK government. Faced with growing unease about the coming public-sector cuts, the Conservative-Liberal Democrat coalition government last week sought morale-boosting rural support by floating plans that would allow farmers to slaughter the animals. In doing so, when it comes to setting polices based on science, ministers have managed only to shoot themselves in the foot.

The plans are designed to arrest the spread of tuberculosis (TB) in cattle, a long-standing problem that the government says cost $£ 63$ million (US\$98 million) in England last year alone.

Announcing the proposal, agriculture minister James Paice said there was no doubt that badgers are a significant reservoir for the disease. He said that action to control the disease in the animals was needed to curb the spread. And he claimed that his decision was based on sound science.

He got the first part right. Badgers do carry and transmit the disease, but the benefits of killing them are much less clear. Mindful of the powerful animal-welfare lobby in Britain, successive governments have cited this lack of evidence in their refusal to bow to pressure from the agricultural community, which has demanded that badgers are controlled. Even the ambitious Randomised Badger Culling Trial (RBCT) experiment, set up in 1997, failed to resolve the matter. Although culling did seem to reduce bovine TB inside target zones, the rate increased outside. In a paper published in February this year, members of the government's Independent Scientific Group on Cattle TB (ISG), now disbanded, concluded that "badger culling is unlikely to contribute effectively to the control of cattle TB in Britain".

The coalition government consulted a separate group of academics, who serve on the Bovine TB Science Advisory Body of the Department for Environment, Food and Rural Affairs. The group concluded in June that the ISG's statement was "problematic" and should not be applied to all culls.

Paice, a former farmer who promised action on bovine TB while in opposition, prefers this interpretation, even though it falls far short of endorsing a cull. To deal with the conflicting views of the trials so far, Paice has devised a new solution. His cull strategy has not been tested - by anyone. Rather than the RBCT's well-organized teams working to eradicate badgers in a controlled manner, Paice foresees consortia of farmers given licences to blast away as they see fit. Farmers will have to fund the work themselves, and the government's own figures show that the costs to farmers will outweigh the financial gains. This must raise serious doubts about the long-term viability of controlling badgers in this way. Vaccination could be used, but Paice admits that this may not be practical or effective. And, as he reduced planned vaccine studies in June from six sites to one, that situation is unlikely to change soon.

Paice is wrestling with a difficult issue. The former Labour government also stumbled over the science of badger culling. After the ISG's final report came out strongly against a cull, a team including the former chief scientific adviser David King reached the opposite conclusion. The Labour government eventually decided not to force the issue in the way that Paice and his colleagues seem determined to do now.

The fate of badgers may not be the most pressing issue facing UK researchers today. But the handling of the situation offers the first clue about how the government will approach scientific advice. It should leave those who promote evidence-based policy feeling anxious. With weightier topics such as climate change, transgenic crops and research funding on their to-do list, ministers need to wise up, and fast.

\section{Nature's new look}

$\mathrm{M}$ agazines aren't dead! Those who look forward to a weekly package of material that they can read whenever and wherever it suits, and without the need to connect to the Internet and charge batteries, remain safe with Nature in print. Trees die in order for us to sustain this habit, and so we all hope that versions supplied over the Internet will allow us eventually to abandon print on paper. But the format of a print magazine, whatever the medium on which it is read, has its own value, which is no doubt why more than 1 million PDFs of articles in Nature are downloaded every month. (A similar number are downloaded in full text.)

Readers can also access the print-originated format in a new and highly readable digital edition (see nature.com/rediscover - registration needed). And an iPad app for Nature is in the pipeline.

This week's issue demonstrates our commitment not only to sustaining Nature as a magazine, but also to renewing it. In recent months, observant subscribers will have noticed small changes. Today, we present a new look, a clearer structure and new types of content. The online navigation, landing pages and information for authors have also been redesigned.

The underlying goal is greater clarity in the reading experience. Nature's readers get ever busier, so they need to know as quickly as possible where to find the content they want and what a particular item is offering. All of the changes we have made are to this end.

The magazine is now structured in a clearer way. The introductory material has been reduced to the Table of Contents, plain and simple.
A new section, called This Week, contains Nature's Editorials as well as summaries of recent developments in and around science. It also includes a new page - World View - in which external authors give prompt personal perspectives on live issues.

More analytical and reflective content, presenting developments in the world of science in greater depth, appears in the section of journalism, which is made up of News in Focus and News Features. The Comment section provides a forum for essays, debates, reviews and correspondence.

The Research section includes accessible summaries of the latest research articles available online, News \& Views, review articles and the primary-research content of Nature - its Articles and Letters. The Careers section, offering guidance to young scientists pondering the job market, and Futures - our back page of science fiction - complete the package.

Within these sections we have tried, in the redesign of our layouts and key elements, to ensure that a reader easily gains a clear idea of why he or she should be reading an article. We've created space for more descriptive headlines and other display elements that allow a reader to get a quick sense of what an article has to say and who its authors are. The new design also emphasizes the use of charts and graphics that offer a quick summary of the key data underlying an opinion piece or news story. It allows for more inventive, attractive pages as well.

Both in print and online, these changes have been developed with intensive market research, and with much positive feedback in the process. We have listened and we have changed. We hope that Nature's subscribers will look forward to their weekly magazine all the more.. 